\title{
Research and Reflections on College Mathematics Teaching Based on Information Educational Technology
}

\author{
LI Chang-xing ${ }^{\mathrm{a}}$ \\ ${ }^{a}$ Department of applied mathematics, School of science, Xi'an university of Post and Telecommunications, \\ Xi'an, 710121, China
}

\begin{abstract}
The purpose of this study was to provide a new reform thought of college mathematics teaching. Firstly, the advantages and disadvantages of traditional mathematical classroom teaching in class based on the information educational technology were analyzed in the paper. Secondly, the author proposed that course features, requests for teaching requirements, students' statements and the cultivation of the abilities to analyze and solve problems should be considered when information educational technology was applied to mathematical classroom teaching and integrated with college education theories. Fundamentally, the quality of college mathematics teaching can be promoted steadily.
\end{abstract}

Index Terms: Information Educational Technology; Mathematics Teaching; Effective Integration; Reflection

(C) 2011 Published by MECS Publisher. Selection and/or peer review under responsibility of the International Conference on E-Business System and Education Technology

\section{Introduction}

With the rapid progress of science and technology, information educational technology is increasingly applied to the teaching process and it extracts greater promises and application value in combination with teaching[1-4]. The application of information educational technology offers students full-range, multi-channel, and the most direct audio and visual experiences, which is the natural trend of the development of higher education. Various education director branches give more attention to the application of information educational technology to the teaching process. Undergraduate Teaching Evaluation and Fine Course Construction projects are in demand for the application of information educational technology. Issues such as altering the obsolete teaching methods and promoting the students' interests in learning are always being discussed. In the National College Mathematics Teaching Seminar held in Xi'an Jiaotong University in 2004 and several National College Mathematics Teaching Forums held recently, the experts and academicians proposed the following questions: "Is it suitable for information educational technology to be applied to mathematics teaching? How is information educational technology integrated with the college mathematics teaching process? How would the advantages of information educational technology be used fully so as to Corresponding author:

E-mail address: ${ }^{\mathrm{a}}$ shuxueshiyanshi@163.com 
examine the modes and methods of college mathematics teaching combined with information educational technology while retaining the effective teaching methodologies in traditional college mathematics teaching and reinforcing the cultivation and promotion of the abilities of the students in logic thinking, reverse thinking, divergent thinking, abstract thinking and the abilities of analyzing and solving problems?"[4]. These are the questions to be answered in college mathematics teaching.

\section{Traditional Teaching Methods and Approaches Cannot Meet the Demands of Teaching Reform}

In the classroom the way of using "language, blackboard and chalk" has dominated college mathematics teaching. Under this mode of teaching, however, some of students cannot receive, understand and master the stresses and difficulties of the teaching content so that find it difficult to learn[5]. Take the teaching of Space Analytic Geometry and Multivariate Calculus for example, knowledge such as space-like surface construct and objects formed by space-like surfaces and the shapes of boundary surface of objects is closely related to the learning of Space Analytic Geometry, multiple integral and the sustained courses. On the other hand, the simple teaching methods of traditional blackboard plus chalk cost too much time in class. Take the teaching of linear algebra for example, the solution to linear equations, matrix and determinant calculation needs too much writing, contains too many formulas, and often repeats drawing graphs; thus, reducing the information in class and the time for students to discuss and communicate with the teachers, resulting in the phenomenon of low efficiency and poor performance[6].

Recently, with the continuous progress of science and technology, college students need to become familiar with and master more knowledge about science and technology. Therefore, the time for college mathematics is reduced. Under the precondition of maintaining teaching quality and how to improve classroom information so as to fulfill the teaching tasks requested by the teaching syllabus; and how to better the boring teaching approaches so as to arouse students' interests in learning mathematics and stimulate happy learning, one of the issues to be answered of college mathematics teaching reform is to investigate effective teaching modes, teaching approaches and devices based on the condition of informational educational technology, which is also the responsibility of mathematics educators.

\section{3. information Educational Technology Is the Important Methodology and Means to Further the Reform of College Mathematics Teaching}

The 21 st century is an era of rapid progress in information technology. With the popularity of computers and the application of mathematics software, the society is undergoing an unprecedented revolution, which brings opportunity for teaching and educational reform. Information educational technology is based on the theory of modern educational theories, which stresses developing students' active role in learning. Rational application of educational technology can arouse students' learning interests and aim at creating an environment in which students can participate so that acquiring knowledge, developing intelligence and quality cultivation can be unified. In the classroom, learning information can be feedback to teachers through networks to implement three-dimensional information exchanges between teachers, students, and teaching materials so as to reach the teaching target. Teaching media is a kind of carrier of knowledge, which is the assistance tool of teachers teaching as well as the acknowledging tool of students' learning. Teaching media is of various forms with similar functions. The rational and flexible application of modern educational technology in mathematics teaching is helpful in perfecting the course teaching structure, fully improving classroom teaching efficiency and cultivating students' creativity and getting them to participate in the application of informational educational technology. 


\section{The Application of Informationalized Educational Technology in Furthering College Mathematics Teaching Reform}

The audio and visual function of informational educational technology can be fully used. For example, the related reading material of each chapter, the experience of some relevant mathematicians, the foundation of some important mathematics' theories and their application can be shown very well. In addition, through rational use of informational educational technology to assist teaching, a better teaching environment is created, which is effective for students to do research and investigate actively and stimulate students' enthusiasm of acquiring knowledge. With the aid of information educational technology, the means of graphs' moving, positioning, flashing, synchronous explanation and color changing can be used to express teaching content. For example, in teaching Space Analytic Geometry, teachers can make some courseware, e.g., a set of animated simulations of rotating, translating, overlapping, and flashing to explain the knowledge of conicoid. The desired graphs are illustrated vividly so as to be easily understood by students. Combined with necessary explanation and elegant music, students can personally experience three-dimensional effects. Through heuristic questioning students are guided to think actively and try to find out the internal relations among the graphs and the reasoning of the relevant computing formulas. In college mathematics teaching, whether the stresses and difficulties can be worked out or not, is the key to the acknowledgement of teaching content. The iconicity, repeatability of informational educational technology and its advantage of surpassing space and time limits can be fully made use of to protrude the teaching stresses and simplify the difficulties in teaching. What is more, the powerful functions of the campus network can be used rationally. Multimedia courseware can be uploaded on the network. Various forms of multiple choices, blank-filling, and true or false questions can be set in the exercises and the software will judge the students' answers. Students can discuss with teachers via the educational network. In this way students can work actively instead of passively, which truly arouses the students' interests in learning so as to reach the target of promoting the teaching quality of college mathematics.

\section{Myths about the Application of Informationalized Educational Technology in College Mathematics Teaching}

Due to the abstractness, formalization and logic of mathematics, the course books omit the discovery process of the knowledge of mathematics. The cultivation of students' creativity is empty talk, if teachers adopt a method copying writings on the blackboard without the thoughts and methods of informational educational technology; thus, teachers are unable to direct the students to examine and think actively. Particularly when information educational technology is used, classroom pace is obviously quickened, resulting in positive effects and the increase of the rate of poor students to comprehend. Therefore, the application of informational educational technology in college mathematics teaching has to be under the guidance of modern educational theories.

The teaching process can not be too fast or too intense, which are both negative in exerting students' active and creative thinking. According to teaching theories, the amount of knowledge that students learn in a session should be controlled. The rapidness and intensity of teaching will lead to too much stimulation, which arouse students' fragility or even causes illness and have a negative impact on learning. Students may lose the confidence of mathematics learning. Moreover, students will find it difficult to take notes, which is negative in reviewing after class. The fast pace of lecturing makes it impossible for students to think fully; thus, reducing the active parts of learning by students and oppressing students' inspiration. Therefore, starting from the degree of the difficulties of teaching content and students' actual statements, teachers should insist on lecturing intensively and to encourage thinking according to the planned content of the teaching syllabus. Particularly when explaining the proof process of theorems and their difficulties, teachers should leave enough time and space for the students to think so as to exert students' activity and cultivate their creative thinking.

In teaching, a single multimedia courseware demonstration can have a negative impact on the contents and the methods for demonstration should be carefully chosen. Nor can demonstration replace the training of 
thinking. What should be noted is that informational educational technology offers first an image, whose advantage is better for the cultivation of students' imaginative thinking.

All in all, college mathematics teaching is the teaching of mathematical thinking activities, which stresses the cultivation of students' thinking abilities and creativity. So space and time should be given to students for thinking. It is not true that the more information educational technology is applied, the better it is. Instead, its application should be proper and in the right place. If all the conclusions and regulations are shown by the way of information educational technology, students' thinking space will be narrower and narrower, resulting in the failure of the aim of promoting the quality of college mathematics teaching.

\section{Reflections on the Integration of Informationalized Educational Technology with College Mathematics Teaching}

There are many advantages of the application of information educational technology in college mathematics teaching. But if we ignore the features of mathematics in teaching and put too much stress on the role of information educational technology or completely rely on it, then it is improper. It is particularly important to make good use of information educational technology in college mathematics courses. Because mathematics is abstract, accurate and precise, mathematics teaching is not only related to conveying mathematics knowledge but also related to the cultivation of students' mathematical thinking and creative spirit. Mathematics stresses abstract generalization, deductive reasoning, and flexible application. If information educational technology is abused, students will not understand the essence of mathematics. Then, students will find it boring and lose interests in learning mathematics.

In recent years, due to college expansion, the quality of students is decreasing. With the practice of the credit system, many universities are carrying out educational reform, especially with courses. Generally, the time for mathematics is reduced while contents are not condensed and standards are retained. People hope to guarantee the quality of teaching under these premises. It is under the conditions that information educational technology is emerging. Recently, evaluation on undergraduate education and the development of the best courses carried out by the Ministry of Education, demand highly for the application of information educational technology in teaching. And it has been regarded as an important approach to promoting teaching reform because of its characteristics of being informational, fast and vivid.

Teachers are supposed to accomplish the requested teaching task in limited class time. Some math teachers are copying the notes when making courseware so as to reduce the process of writing on the blackboard, to quicken the pace of lecturing, and to increase the amount of illustrations. Thus, the aim of improving teaching efficiency is reached. But it always produces exactly the opposite results. The new type of "pouring in class" will be worse than the traditional "pouring in class". It is disadvantageous for improving the teaching quality of mathematics in full scope, which should be noted by all the teachers.

How do we integrate informational educational technology with college mathematics teaching?

The author has been teaching college mathematics for many years. According to him, the integration of informational educational technology with college mathematics teaching is quite good. The proper, rational and scientific application of information educational technology in the teaching process can improve the efficiency of classroom teaching and it is an important approach to the improvement of the teaching quality of college mathematics.

It is well known that the contents of college mathematics are mainly formed by problems, concepts, theorems and their proof, applications, and illustrations. Applying information educational technology and developing delicate multimedia courseware can lead to better teaching effects than traditional teaching methods. Firstly, in order to make good multimedia courseware, much effort, money and critical thinking will be used. Therefore, the existing multimedia courseware is not of high quality. Even some national best courses are lacking in high quality multimedia courseware; thus, resulting in the myth that information educational technology is no better than traditional teaching methods. According to the author, the description of the problem, the roadmap and the methodology of problem solving, and the application of mathematics should be 
introduced to the students by the way of making full use of the advantages of information educational technology so that students can formulate great interests in mathematics; thus, their strong desire of knowledge learning is inspired. The academies who regard traditional teaching methods better than information educational technology usually focus on the explanation to theorems, proof and illustrations. It is known to all that blackboards are mainly for writing and drawing diagrams. In the case of drawing a diagram, we can demonstrate the whole process of drawing if the courseware is elaborately developed, which is apparently better and more precise than what the teacher draws on the blackboard. Secondly, the explanation to theorems, proof and illustration, generally in the aspect of the theorems and their proof process, is shown on the screen so that students use less time to think it over. To solve the problem, courseware can be developed in the form of separated words, separated sentences, separated markers and separated formulas according to the teaching contents. When teachers show the contents on the screen, we should control the pace of lecturing according to the actual understanding capabilities of the students, stress the essential parts and simplify the difficulties so that students will have adequate time to think. While conveying the contents, inheriting and developing the advantages of chalk and blackboard, the teacher can write the important concepts and theorems on the blackboard for later revision.

In mathematics class, we should not completely deny the role of chalk and blackboard. Nor should we deny the role of information educational technology. The roles and the disadvantages of the application of the traditional mathematics teaching method of "speech+blackboard+ chalk" and information educational technology should be correctly understood. In teaching practice, the advantages of traditional teaching methods and information educational technology should be fully exerted and absorb the strong points of both and offset their weakness. Combining the traditional method and information educational technology and continuing investigating and practicing, we hold the belief that information educational technology will play an increasing role in enhancing the teaching quality of college mathematics teaching.

\section{Acknowledgements}

Teaching Reform and its Practice of Mathematics Foundation Courses in Higher Polytechnic schools (Higher Education of Ministry No.2007-143);Teaching Reform Research Project of Higher Education in Shaanxi Province (Higher Education of Shaanxi No.2007-68;Natural Science and Technology Research and Development Project of Shaanxi Province (No.2008K01-33); The National Natural Science Foundation of Education Committee of Shaan Province(No. 09JK716,No.09JK723)

\section{References}

[1] Bi Zhiwei, "Talk on Upgrading the Teaching Devices," The University Mathematics Courses Forum, China (2005). Beijing:Higher Education Press, 2006, pp.104-108. (in Chinese)

[2] Tian Liping, "Discussion and Practice on the Teaching Reform of Higher Mathematics Course," The University Mathematics Courses Forum, China(2004). Beijing:Higher Education Press,2005,pp.176-179. (in Chinese)

[3] Zhou Changsheng, "Thoughts on the Positive and Negative Effects of Higher Education on College Mathematics Teaching,"Advanced Mathematics Research. 2002,(5), pp.21-23. (in Chinese)

[4] Fan Qingshan,“ Key to Enhancing the Teaching Quality Is Enhancing the Classroom,'Teaching. China College Teaching,2003,(11): pp.12-14. (in Chinese)

[5] Wang Xiaoyin, "A Proper Orientation of Multi-media Classroom Teaching of College Mathematics,”Higher Agriculture Education, 2002,(12): pp.3-5. (in Chinese)

[6] Xu Zhongben, "Education of College Mathematics on the background of informatization," The University Mathematics Courses Forum, China(2009). Beijing:Higher Education Press,2010, pp.8-11. (in Chinese) 